\title{
Arteriovenous Malformations of the Posterior Fossa : Focus on Surgically Treated Patients Presenting with Hemorrhage
}

\section{Pohjola, Anni}

2018-08

Pohjola , A , Lehto , H , Hafez , A , Oulasvirta , E , Koroknay-Pál , P \& Laakso , A 2018 , ' Arteriovenous Malformations of the Posterior Fossa : Focus on Surgically Treated Patients

Presenting with Hemorrhage ' , World Neurosurgery , vol. 116 , pp. E934-E943 . https://doi.org/10.1016/j.wneu.2018

http://hdl.handle.net/10138/303993

https://doi.org/10.1016/j.wneu.2018.05.138

cc_by_nc_nd

acceptedVersion

Downloaded from Helda, University of Helsinki institutional repository.

This is an electronic reprint of the original article.

This reprint may differ from the original in pagination and typographic detail.

Please cite the original version. 


\section{Accepted Manuscript}

Arteriovenous Malformations of the Posterior Fossa - Focus on the Surgically Treated Patients Presenting with Hemorrhage

Anni Pohjola, BM, Hanna Lehto, MD, PhD, Ahmad Hafez, MD, Elias Oulasvirta, BM, Päivi Koroknay-Pál, MD, PhD, Aki Laakso, MD, PhD

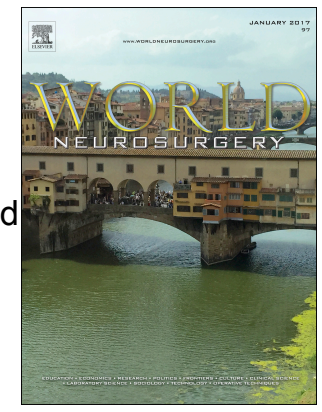

PII: $\quad$ S1878-8750(18)31091-X

DOI: $\quad$ 10.1016/j.wneu.2018.05.138

Reference: WNEU 8199

To appear in: World Neurosurgery

Received Date: 26 February 2018

Revised Date: 18 May 2018

Accepted Date: 19 May 2018

Please cite this article as: Pohjola A, Lehto H, Hafez A, Oulasvirta E, Koroknay-Pál P, Laakso A, Arteriovenous Malformations of the Posterior Fossa - Focus on the Surgically Treated Patients Presenting with Hemorrhage, World Neurosurgery (2018), doi: 10.1016/j.wneu.2018.05.138.

This is a PDF file of an unedited manuscript that has been accepted for publication. As a service to our customers we are providing this early version of the manuscript. The manuscript will undergo copyediting, typesetting, and review of the resulting proof before it is published in its final form. Please note that during the production process errors may be discovered which could affect the content, and all legal disclaimers that apply to the journal pertain. 
ARTERIOVENOUS MALFORMATIONS OF THE POSTERIOR FOSSA - FOCUS ON THE SURGICALLY TREATED PATIENTS PRESENTING WITH HEMORRHAGE

Anni Pohjola, BM, Hanna Lehto, MD, PhD, Ahmad Hafez, MD, Elias Oulasvirta, BM, Päivi Koroknay-Pál, MD, PhD, Aki Laakso, MD, PhD

Department of Neurosurgery, Helsinki University Hospital, and Clinical Neurosciences, University of Helsinki

Correspondence:

Aki Laakso, MD, PhD

Department of Neurosurgery

Helsinki University Hospital

PO Box 266

Topeliuksenkatu 5

00260 Helsinki

Finland

Email: aki.laakso@hus.fi

Tel: $+358-50-4272895$

Declarations of interest: none.

The study was supported by Finnish government funding for academic health care research (grant TYH2017235).

Keywords: Arteriovenous malformation, cerebellar haemorrhage, intracerebral haemorrhage, infratentorial, posterior fossa, stroke 


\section{INTRODUCTION}

Brain arteriovenous malformations (AVM) are rare vascular lesions, with prevalence rate estimates of $0.02 \%$ all the way to $0.2 \% .^{1,2}$ They predispose often young and otherwise healthy patients to several complications, handicaps and even death. Patients are typically in their third or fourth decade of life, ${ }^{3-5}$ which further magnifies the damage of long-term illness, both to the patient and the healthcare system. Infratentorial AVMs, consisting of $5-15 \%$ of all intracranial AVMs ${ }^{4,6-8}$, have shown in studies to bear even more considerable mortality and morbidity rates than their supratentorial counterparts $^{3,9-11}$. They also have a much higher rupture rate ${ }^{4,12}$, even as high as 8 $12 \%$ a year, ${ }^{3,6,13}$ thus, they require prompt clinical observation and treatment. On the other hand, the often eloquent location and complicated cerebrovascular anatomy of these lesions, force clinicians to ponder whether to tackle them with surgery, embolization, radiation therapy, combination of these, or rather preserve the option of conservative treatment. Surgical resection is considered the main treatment modality for most infratentorial AVMs, given that they often present already ruptured. ${ }^{9,14}$ Stereotactic radiosurgery, however, is often held as the primary treatment modality for AVMs in brainstem and deep cerebellar nuclei, due to the significant postoperative effects of surgery in the eloquent area. ${ }^{10,13,15}$ However, radiosurgical cure requires several years to develop, whereas successful surgical resection yields an immediate obliteration. ${ }^{16}$ Preoperative embolization may be a useful adjunct in large and complex AVMs. ${ }^{10,13}$

Studies consisting of outcome analyses of treated patients with infratentorial AVMs are scarce. Also, because of the rarity of the disease, these studies usually consist of relatively small patient samples, which further magnifies the need of similar studies in different populations. In this study, we analysed all infratentorial AVM patients admitted to our academic neurosurgical department from 1990 forward. For statistical analyses we further specified the cohort into 38 consecutive patients with ruptured posterior fossa AVMs treated surgically in our center. The 
purpose of this study was to analyse the preoperative features influencing the clinical outcome after surgery at the early recovery stage and at last follow-up. Also, morphological and clinical data were analysed to identify the typical nature of these lesions. The high-quality public health care system in our country provides accessible and extensive hospital records and vital statistics. Also, the relatively steady and homogeneous population offer an excellent basis for clinical research. In addition, all AVMs are treated in university hospitals with defined catchment areas.

\section{PATIENTS \& METHODS}

\section{Patients and Follow-up}

Between 1942 and 2014, 805 patients with brain AVM were admitted to our neurosurgical department. These patients and their clinical records were collected into a database consisting of demographic, morphological, clinical, treatment and follow-up data. See Figure 1 for the flowchart of patient selection for this study. Six cases with ruptured AVMs were excluded from the surgical cohort and were not part of the statistical analysis. In five of them, the ruptured AVM was not operated. In three of these the AVM was not treated at all, as the clinical condition upon admission was too severe, and the patients deceased soon after. Of the remaining three, in one case with posterior midbrain AVM, the lesion was first embolized and treated with radiosurgery later on. The fifth case, also with posterior midbrain AVM, received only radiosurgery. Sixth case with ruptured AVM was excluded from the analysis, because the surgical treatment was initiated in another hospital abroad, and the patient was transferred to us later on.

Data have been gathered retrospectively from clinical records, and the death certificates were obtained from state authorities to verify the date and cause of death for deceased patients. The 
final outcome data was gathered with questionnaires from patients who were alive and 18 years or older during 2016. This study was approved by the hospital's ethical board. According to national legislation, patient consent is not required for the use of registry data for academic research purposes. However, all alive individual participants gave their informed consent for the use of questionnaire data for this study.

AVM diagnosis was based on angiography (DSA and/or CTA). AVM location classification into either supratentorial or infratentorial (and more specifically into either cerebellar or pontomesencephalic), size, angioarchitecture, associated aneurysms and rupture status were evaluated based on CT and/or MR imaging and angiography. Also, lesions were classified regarding their eloquence. Deep seated lesions located in the brainstem, in deep cerebellar nuclei or in cerebellar peduncles were considered eloquent. The AVM was determined ruptured before admission based on haemorrhage in imaging. Preoperative severity of bleeding was estimated using Hunt \& Hess $(\mathrm{H} \& \mathrm{H})$ scale. ${ }^{17}$ For patients with multiple bleedings in clinical history, the essential bleeding regarding clinical outcome was the one leading to treatment in our center, and its $\mathrm{H} \& \mathrm{H}$ value was used in the analyses. Lesions were evaluated on Spetzler-Martin (S-M) grading system. Patients had control angiograms performed immediately after operation to rule out/detect residual AVM. Glasgow Outcome Scale (GOS) ${ }^{18}$ was used as a measure of outcome for the early stage of recovery (2-4 months after admission). Status was estimated based on hospital patient files and therefore the coarser GOS was used to represent outcome at the early stage. Modified Rankin Scale $(\mathrm{mRS})^{19}$, evaluated based on structured questionnaire obtained in 2016, was used in the evaluation of outcome at last follow-up. However, for Table 4 we reported the last follow-up GOS grades (estimated by using clinical records) to improve the comparability of the studies. For those patients who had died, the date of death was defined as the last follow-up date. Two patients had died of cancer and were not included in the last follow-up analyses. 
Statistical methods

Venous drainage of the lesion was categorized into deep, superficial or both superficial and deep. Lesions with both superficial and deep drainage were considered deep in the dichotomous statistical analyses. The outcome at first follow-up, measured with GOS, was dichotomized and scores $<4$ were considered poor. The mRS grades at last follow-up were also dichotomized, values $<3$ were considered favourable.

The relation between categorical variables and outcome was analysed using Fisher's Exact test. The dichotomous variable of the flow of venous drainage, $\mathrm{H} \& \mathrm{H}$ grade, preoperative S-M grade, hydrocephalus at admission, AVM location, the eloquence of the location and sex were included in these univariate analyses. Mann Whitney U test was used in evaluation of the relation of age and size to outcome. Further hypothesis testing for the variables was done by using logistic regression models. The number of predictor variables included in the model was limited due to the sample size and the risk of overfitting the model. In these models, we included variables, that we hypothesized might influence the clinical outcome; age at admission, the dichotomous grade of the venous drainage, hydrocephalus at admission and preoperative Hunt \& Hess score. Unconditional stepwise method was used to create the final regression model. Participants with missing values regarding a specific variable were not included in analysis of the variable in question. Significance level $<0.05$ was considered statistically significant. The statistical analysis was carried out using IBM SPSS software version 24.0.0.0. for Mac (SPSS, Inc., Chicago, IL). 


\section{RESULTS}

\section{Characteristics of the cohort}

The final cohort consisted of 38 patients with an infratentorial AVM. Their mean follow-up time was 9.7 years (range 7 days - 26 years). Anatomical and demographic data of the cohort are summarized in Table 1. Main symptoms were severe headache $(45 \%, \mathrm{n}=17)$, sudden loss of consciousness $(37 \%, \mathrm{n}=14)$, nausea and vomiting $(5.3 \%, \mathrm{n}=2)$ and focal neurological deficit $(2.6 \%, \mathrm{n}=1)$. For four patients $(11 \%)$ the main symptom was undetermined. Six patients $(16 \%)$ had associated aneurysms and out of these patients three were confirmed to have bleeding caused by it. Twenty-one patients (55\%) were diagnosed with hydrocephalus at admission. Clinical severity of the hemorrhage based on $\mathrm{H} \& \mathrm{H}$ scores at admission are given in Table 2.

\section{Surgical results}

Total extirpation of the AVM was achieved by surgery in 36 patients (95\%). In five of them, second operation was required after control DSA demonstrated a small residual AVM. In one case, only a ruptured, AVM-related aneurysm was ligated and the nidus was later completely obliterated with stereotactic radiosurgery. In another case, late DSA control demonstrated a small residual nidus after preoperative embolization and surgery, which was then successfully treated with radiosurgery. Three patients required permanent CSF shunting. 


\section{Factors influencing clinical outcome after surgery}

Comparing the clinical status of patients at the two follow-up stages, only one patient had improved beyond the early follow-up status (GOS severe disability $\rightarrow$ mRs slight disability, follow-up time 3.7 years) and two had actually deteriorated from favourable to poor outcome within the relatively long follow-up period. One of them had a good recovery status at the first follow-up but had deteriorated to moderate disability (follow-up time 15 years). The deterioration of the other patient might only be because of the different grading systems, since the outcome was moderate disability at both stages at (follow-up time 11 years), thus the magnitude of actual clinical deterioration is impossible to estimate retrospectively. Otherwise patients in the cohort had maintained the outcome between the two follow-up stages, even when taking the different grading systems into account. Also, two patients were dropped out of the last follow-up analyses because their reason of death was not attributed to AVM. Distribution of outcome grades can be found in Table 3.

\section{Early recovery}

See Table 2 for univariate outcome results. Deep venous drainage and high H\&H score significantly predicted poor outcome at first follow-up. High S-M grade did not correlate with early outcome in univariate testing. No significant difference in the severity of the outcome was attributable to size, associated aneurysms, age, location (brainstem vs. cerebellum), eloquence, sex or hydrocephalus at admission.

In the final regression model, old age at admission (OR 1.06, 95\% CI 1.01-1.12, $\mathrm{p}=0.028)$ and deep venous drainage $(\mathrm{OR} 14.5,95 \%$ CI 1.88-111.9, $\mathrm{p}=0.010)$ turned out to be independent 
predictors for poor early outcome. Other tested variables failed show significant association to outcome.

\section{Outcome at last follow-up}

Deep venous drainage was the only variable that correlated significantly with poor late outcome in univariate analyses. Neither the preoperative S-M grade nor H\&H score correlated with outcome at last follow-up. In addition, none of the other tested variables showed significant relation to the outcome in univariate testing.

Also in the final regression model, the only independent variable predicting poor outcome was deep venous drainage (OR 5.00, 95\% CI 1.030-24.28, $\mathrm{p}=0.046$ ). All other tested variables failed to predict outcome significantly.

\section{Deceased patients}

At the end of 2016, six patients had died; two of them of cancer. Four patients had died from AVMrelated reasons; in them, the interval between haemorrhage and death varied from 23 to 55 days. Three of them had severe bleedings (H\&H 4 or 5) from cerebellar AVMs and were unconscious or severely disabled for the whole treatment period. One of them with intraventricular haemorrhage developed a severe vasospasm affecting also supratentorial circulation and died of widespread cerebral ischemia. One patient with S-M grade 2 vermian AVM was admitted with a mild haemorrhage $(\mathrm{H} \& \mathrm{H}$ 2), but suffered a severe re-bleeding immediately after preoperative embolization, and developed widespread brainstem ischemia despite immediate hematoma 
evacuation and complete AVM resection. Notably, none of the patients who died had brainstem AVMs.

\section{Summary of previous posterior fossa studies}

In Table 4 are summarized data about four posterior fossa study cohorts, with different main treatment modalities. The lack of reported items in some of the studies compromised the conduction of the table, however, with the gathered data it can be appreciated, that the patient populations subject to certain treatment modalities differ in terms of multiple characteristics, including lesion size, number of associated aneurysms and presentation S-M score.

Two representative cases are presented in Figures 2 and 3.

\section{DISCUSSION}

Infratentorial AVMs pose a unique clinical challenge: lesions are often located near the eloquent locations of the brainstem and, thus, don't require large haematoma volumes to become lethal. ${ }^{9}$ Also, they most often present with bleeding ${ }^{6,20}$, coursing the treatment into the way of damagecontrol rather than planned, elective resection of the lesion. The shortage of surgical outcome analyses consisting of infratentorial AVMs challenges the rightful assessment of patient's clinical outcome. Evaluation of rupture rates based on natural history studies does not benefit most 
infratentorial patients, whose AVM most often presents already ruptured. This is why our study, consisting of surgically operated patients with ruptured AVMs, comes of importance.

Our study consisted of patients admitted within a 24-year span. During this period, there have been many technological advances, however, their influence on the patient prognosis is most likely not as important as the advances in technology before the 90's. MRI imaging has become more available, even for patients with AVM haemorrhage (obviously excluding the patients in urgent emergency). For the emergency situations, the CT angiography has enabled practically an immediate access to the operating theatres, in comparison to the DSA angiography. ICG (indocyanine green) angiography helps discerning feeding arteries from draining veins, although its value in demonstrating residual nidi is limited. Intraoperative neurophysiological monitoring, as well as neuronavigation may be helpful in selective cases.

\section{Influence of anatomic factors on outcome}

In this series, and also in the existing literature, it has been demonstrated that deep venous drainage poses a significant risk to poor outcome in surgically treated AVM patients. ${ }^{21-23}$ There are several potential explanations for this. AVMs with deep venous drainage often have deep perforating arterial supply, which may be notoriously difficult to deal with during surgery. In addition, posterior fossa AVMs are usually deep-seated lesions located close to deep cerebellar nuclei and brainstem, as opposed to superficial AVMs with purely cortical drainage. Hypothetically, the occlusion of deeply draining arteriovenous shunting may also bring about unexpected effects of reorganization of deep venous system outflow, with more widespread and severe consequences than in the case of cortical outflux problems. 
Interestingly, size and location themselves did not influence outcome in our study. Partially, this may be due to the lack of statistical power in this rather small series. In addition, the variability in size is mandatorily smaller than in supratentorial AVMs, due to obvious spatial constraints. The fact that size did not affect outcome probably also explains the lack of association between S-M grade and outcome, as size is a major contributor to final S-M score. Eloquence is a reasonable contributor to outcome, however, it did not yield statistical significance in our analyses. Bleeding in an eloquent area is more likely to course the treatment decision towards the conservative direction, making the surgical subcohorts of eloquent locations even smaller. In our sample, we had three patients with eloquent AVMs who did not receive surgical treatment for their lesion. Two of them had died soon after the rupture. However, as mentioned in the Results section, none of the operated patients with brainstem AVM had died within the follow-up period. The lack of association between eloquence of the lesion and outcome might also influence the incapability of S-M to correlate with outcome, since eloquence is also one of the contributors to the S-M score.

\section{Association between young age and favourable outcome}

In our series, we witnessed a weak association between young age at admission and favourable outcome status at the early recovery stage, 2-4 months after surgery. This relation was not apparent in univariate tests but appeared in the regression model. A similar association has occurred also in other studies, supporting the significance of our results as well. Lawton et al. have reported a positive correlation between young age and favourable recovery from AVM surgery. ${ }^{24}$ Their study consisted of both supratentorial and infratentorial patients and included also unruptured AVMs. With a similar cohort to setting in 445 microsurgically treated AVMs, Ren et al. have also reported an association between young age and favourable postoperative status. ${ }^{21}$ 
Naturally, clinical status of the patient tends to deteriorate in time, as factors other than purely the AVM and the transient postoperative consequences, start to accumulate and influence patient's condition. Also, increased neurological recovery and plasticity, and the lack of other medical co-morbidities in younger patients instinctively explain most of the correlation. However, given the relatively young mean age of our patient sample, and AVM patients in general, one could assume that the effect of aging would not have as serious an influence on late outcome as it has in other vascular diseases, in which the pathophysiology is more closely related to age and lifestyle. Whether younger patients enjoyed better outcomes because of the better preoperative baseline or the better recovery from rupture and surgery, cannot be addressed in the light of our data.

The severity of bleeding and the outcome

Hunt \& Hess score was originally created to demonstrate the severity of aneurysmal subarachnoid haemorrhage. ${ }^{17}$ The haemorrhage severity in the group of posterior fossa AVMs is often of aggressive nature ${ }^{9}$, as already mentioned. Since AVM-specific scales to assess haemorrhage severity do not exist, we chose the $\mathrm{H} \& \mathrm{H}$ scale as it is based mainly on symptomatology and the level of consciousness after bleeding, and hence likely to be valid regardless of the source of bleeding. There is a recently published, more general scoring system predicting outcome of ruptured AVMs, which also consists the influence of the risk of surgical treatment. ${ }^{24}$ Therefore, we didn't consider it as useful as the $\mathrm{H} \& \mathrm{H}$ scale, to assess purely the severity haemorrhage.

In our cohort, the scores at admission were relatively evenly distributed to all five grades. As expected, high preoperative grades proved a rather significant relation to poor outcome status at the early recovery stage. In our study, the grade showed association only to the early recovery, but not to the outcome at last follow-up. 


\section{Results in previous posterior fossa studies}

Ding et al. conclude in their radiosurgical study, that subsequent embolization with radiotherapy yields worse results than radiosurgery alone for cerebellar AVMs. ${ }^{25}$ They also report, that subsequent microsurgical resection was associated with better obliteration rates (HR 1.81, 95\% CI $1.20-2.73, \mathrm{p}=0.005)$. Their obliteration rate of $72 \%$ includes also the $23(38 \%)$ patients treated with either microsurgery or endovascular therapy prior to radiotherapy. Also, the final rate was received after 7 years of follow-up, with the actuarial rates at three and five years being $51 \%$ and $71 \%$, respectively. They had determined outcomes as the combination of total AVM obliteration, no postradiosurgery haemorrhage and no permanent radiation induced changes (RIC). ${ }^{26}$

In their endovascular AVM study Robert et al. also reported only the multimodal treatment obliteration rate of $73 \%$, which included $15(22 \%)$ patients with subsequent radiotherapy or microsurgery. ${ }^{27}$ The microsurgery included an evacuation of the residual nidi in nine (13\%) patients. Stereotactic radiosurgery was used as a complementary treatment for six (8.7\%) patients.

Finally, in their study of multimodal treatment options, Kelly et al. concluded that for S-M grade III-IV AVMs, radiosurgery alone was associated with worse results than when endovascular and/or microsurgical therapy was included in the treatment. ${ }^{13}$ Multimodality in their study nearly tripled the cure rate, still keeping the complication rate acceptable. However, their radiosurgical subgroup consisted of only 14 patients and this might bias the results. Multimodality was the treatment strategy for 34 patients, and out of them $21(62 \%)$ were cured. The obliteration rate for the whole study population, including patients treated with radiosurgery only, was $52 \%$.

In our study, the obliteration rate in the purely surgical group was 100\% (26/26). There were $12(33 \%)$ multimodal patients, out of whom two $(5.3 \%)$ did not receive total extirpation, leaving the obliteration rate for the whole cohort to $95 \%$. 
The cohort characteristics in the studies are substantially different, thus the grades are not directly comparable. Furthermore, there are at least two types of selection biases present. First, the most demanding lesions are more prone to multimodal treatment, since they might require presurgical procedures or the residual nidi might be needed to eliminate with another modality after an unsuccessful operation. Second, patients are treated with certain modalities because of the existing literature and expertise, driving modern treatment cohorts into automatically representing certain types of patients.

However, there are similarities in the lesion characteristics between the endovascular and microsurgical treatment groups, yet the outcomes and obliteration rates seem to support microsurgical approach. Notably, there were more associated aneurysms and S-M grade IV lesions in the endovascular group, which might worsen the follow-up GOS grades. However, the short follow-up period of the endovascular group might underestimate the effect of unobliterated lesions and the persisting rupture risk, which is immediately eliminated with a successful surgical procedure.

Radiosurgery usually requires multiple procedures, which have shown to associate with worsened outcome ${ }^{10}$, and the total occlusion might take years to develop, pertaining the risk of rupture. ${ }^{16}$ However, for lesions in eloquent areas of the brainstem and deep cerebellar nuclei, it is often preferred over microsurgery and endovascular therapy, owing to the postoperative effects in the area. ${ }^{10,13}$

Comparing the four studies, the obliteration rates appear best in the surgical group and the GOS grades are comparable to the endovascular group. Furthermore, with the exception of highgrade (S-M IV-V) or deep-seated lesions, previous studies have concluded that the complication risks don't significantly differ between modalities, ${ }^{28,29}$ even in the posterior fossa region. ${ }^{13}$ As a monotherapy, endovascular or radiosurgical modalities are less likely to be as effective as microsurgical resection, with the exception of stereotactic radiosurgery in the eloquent areas of the 
posterior fossa. ${ }^{10,13,15}$ As Kelly et al. proposed, the inclusion of subsequent treatments should be discussed in a multidisciplinary meeting, since the increased number of procedures have shown to associate with worsened clinical outcome..$^{10,13}$

\section{Limitations of the study}

The inevitably small size of the cohort could possibly leave many reasonable influencers of the outcome insignificant in the analyses. Also, the effect might be the opposite and produce falselypositive results. This underlines the importance of patient selection to the cohort and also the rightful interpretation of the results.

Also, for methodological reasons, statuses were analysed using different grading systems, for which the borderline grades have some overlapping, and might not be able to catch the patients whose improvement or decline falls in-between the borders of these grading systems. This could be one explanation why certain factors did not appear significant at both the follow-up stages.

The retrospective nature of this study could also be interpreted as a limitation. However, the disadvantages usually associated with retrospective studies, such as missing variables, recall or misclassification bias do not apply to our study, since the data was collected using clinical records, which have been created at the time of the events and remain unaltered. Also, only few patients in the cohort had with missing variables, which were noticed during the statistical analyses, and these patients were excluded from the analyses. 


\section{IN CONCLUSION}

AVMs of the posterior fossa are rare and challenging lesions, with aggressive natural history. They require prompt management of both the infratentorial bleeding and the lesion itself. However, their rarity makes data collection and the conduction of clinical and statistical analyses difficult.

In the light of our data, venous drainage pattern has the most significant influence on patient's outcome after surgery, favouring patients with lesions with only cortical drainage. Also, it appears, that patient's age at admission and the severity of the bleeding, associate with the outcome after surgery. Our data show that even after a rupture of a treacherous infratentorial, even eloquently located AVM, patient's clinical condition can reach favourable outcomes with surgical intervention. Still, to gain a sufficient magnitude of predictive power for these rare lesions and their outcomes, we need more similar outcome analyses from other research groups and patient cohorts.

\section{References}

1. Al-Shahi R, Fang JS, Lewis SC, Warlow CP. Prevalence of adults with brain arteriovenous malformations: a community based study in Scotland using capture-recapture analysis. $J$ Neurol Neurosurg Psychiatry. 2002;73(5):547-551.

2. Berman MF, Sciacca RR, Pile-Spellman J, et al. The epidemiology of brain arteriovenous malformations. Neurosurgery. 2000;47(2):389-396; discussion 397. 
3. Hernesniemi JA, Dashti R, Juvela S, Vaart K, Niemela M, Laakso A. Natural history of brain arteriovenous malformations: a long-term follow-up study of risk of hemorrhage in 238 patients. Neurosurgery. 2008;63(5):823-829; discussion 829-831.

4. Khaw AV, Mohr JP, Sciacca RR, et al. Association of Infratentorial Brain Arteriovenous Malformations With Hemorrhage at Initial Presentation. Stroke. 2004;35(3):660-663.

5. Gross BA, Du R. Natural history of cerebral arteriovenous malformations: a meta-analysis. J Neurosurg. 2013;118(2):437-443.

6. Arnaout OM, Gross BA, Eddleman CS, Bendok BR, Getch CC, Batjer HH. Posterior fossa arteriovenous malformations. Neurosurg Focus. 2009;26(5):E12.

7. Fleetwood IG, Steinberg GK. Arteriovenous malformations. Lancet. 2002;359(9309):863873.

8. Kouznetsov E, Weill A, Ghostine JS, Gentric JC, Raymond J, Roy D. Association between posterior fossa arteriovenous malformations and prenidal aneurysm rupture: potential impact on management. Neurosurg Focus. 2014;37(3):E4.

9. Abla AA, Nelson J, Rutledge WC, Young WL, Kim H, Lawton MT. The natural history of AVM hemorrhage in the posterior fossa: comparison of hematoma volumes and neurological outcomes in patients with ruptured infra- and supratentorial AVMs. Neurosurg Focus. 2014;37(3):E6.

10. da Costa L, Thines L, Dehdashti AR, et al. Management and clinical outcome of posterior fossa arteriovenous malformations: report on a single-centre 15-year experience. J Neurol Neurosurg Psychiatry. 2009;80(4):376-379.

11. Yang W, Caplan JM, Ye X, et al. Racial Associations with Hemorrhagic Presentation in Cerebral Arteriovenous Malformations. World Neurosurg. 2015;84(2):461-469. 
12. Fullerton HJ, Achrol AS, Johnston SC, et al. Long-term hemorrhage risk in children versus adults with brain arteriovenous malformations. Stroke. 2005;36(10):2099-2104.

13. Kelly ME, Guzman R, Sinclair J, et al. Multimodality treatment of posterior fossa arteriovenous malformations. J Neurosurg. 2008;108(6):1152-1161.

14. Lawton MT, Abla AA. Management of brain arteriovenous malformations. Lancet. 2014;383(9929):1634-1635.

15. Starke RM, Ding D, Kano H, et al. International multicenter cohort study of pediatric brain arteriovenous malformations. Part 2: Outcomes after stereotactic radiosurgery. $J$ Neurosurg Pediatr. 2017;19(2):136-148.

16. Kano H, Kondziolka D, Flickinger JC, et al. Stereotactic radiosurgery for arteriovenous malformations, Part 6: multistaged volumetric management of large arteriovenous malformations. J Neurosurg. 2012;116(1):54-65.

17. Hunt WE, Hess RM. Surgical risk as related to time of intervention in the repair of intracranial aneurysms. J Neurosurg. 1968;28(1):14-20.

18. Jennett B, Bond M. Assessment of outcome after severe brain damage. Lancet. $1975 ; 1(7905): 480-484$.

19. van Swieten JC, Koudstaal PJ, Visser MC, Schouten HJ, van Gijn J. Interobserver agreement for the assessment of handicap in stroke patients. Stroke. 1988;19(5):604-607.

20. Drake CG, Friedman AH, Peerless SJ. Posterior fossa arteriovenous malformations. J Neurosurg. 1986;64(1):1-10.

21. Ren $Q$, He M, Zeng $Y$, Liu Z, Liu H, Xu J. Microsurgery for intracranial arteriovenous malformation: Long-term outcomes in 445 patients. PLoS One. 2017;12(3):e0174325.

22. Tong $\mathrm{X}, \mathrm{Wu}$ J, Cao $\mathrm{Y}, \mathrm{Zhao} \mathrm{Y}, \mathrm{W}$ ang $\mathrm{S}$. New predictive model for microsurgical outcome of intracranial arteriovenous malformations: study protocol. BMJ Open. 2017;7(1):e014063. 
23. Shotar E, Debarre M, Sourour NA, et al. Retrospective study of long-term outcome after brain arteriovenous malformation rupture: the RAP score. J Neurosurg. 2017:1-8.

24. Lawton MT, Kim H, McCulloch CE, Mikhak B, Young WL. A supplementary grading scale for selecting patients with brain arteriovenous malformations for surgery. Neurosurgery. 2010;66(4):702-713; discussion 713.

25. Ding D, Starke RM, Yen CP, Sheehan JP. Radiosurgery for cerebellar arteriovenous malformations: does infratentorial location affect outcome? World Neurosurg. 2014;82(12):e209-217.

26. Starke RM, Yen CP, Ding D, Sheehan JP. A practical grading scale for predicting outcome after radiosurgery for arteriovenous malformations: analysis of 1012 treated patients. $J$ Neurosurg. 2013;119(4):981-987.

27. Robert T, Blanc R, Ciccio G, et al. Endovascular treatment of posterior fossa arteriovenous malformations. J Clin Neurosci. 2016;25:65-68.

28. Potts MB, Lau D, Abla AA, et al. Current surgical results with low-grade brain arteriovenous malformations. J Neurosurg. 2015;122(4):912-920.

29. Bradac O, Charvat F, Benes V. Treatment for brain arteriovenous malformation in the 19982011 period and review of the literature. Acta Neurochir (Wien). 2013;155(2):199-209. 


\section{FIGURE LEGENDS}

Table 1. Anatomical and demographic data table. Table consisting of anatomical and demographic data of the final surgical cohort of 38 patients.

Table 2. Outcome univariate analyses table. Contingency table containing the distribution of outcome grades and preoperative Spetzler-Martin grades, preoperative Hunt \& Hess grades and the flow of venous drainage. Also, the results derived from univariate analyses conducted in the final cohort are included in the table.

Table 3. Outcome distribution table. Table of the outcome distribution in the final cohort of 38 patients. Includes both the first follow-up grades evaluated using Glasgow outcome scale and the last follow-up grades classified in moderate Rankin scale.

Table 4. Summary of previous posterior fossa studies. A summarizing table of four different treatment cohorts consisting of comparable characteristics and results.

Figure 1. Flowchart of patient selection. Flowchart illustrating the patient selection for this study from the Helsinki AVM database.

Figure 2. Case 1. Fourteen-year-old girl, with sudden, severe headache, nausea and weakness on the right upper limb. A) T2-weighted MRI demonstrated intracerebral hematoma in the right cerebellar hemisphere. B, C) DSA performed the following day shows a right-sided cerebellar, Spetzler-Martin grade 2 AVM, fed by right PICA and AICA and draining superficially to right sigmoid sinus. Surgery was performed on the first day after the bleeding via suboccipital retrosigmoid approach, and AVM was resected and hematoma evacuated. D, E) DSA performed the day after the surgery demonstrated complete eradication of the AVM, and no early venous drainage was seen. F) Control MRI performed 3 months after surgery demonstrated a clean surgical cavity 
with no signs of residual AVM, and patient had recovered well with only minor clumsiness on her right arm. At the latest follow-up 14 years later, she had recovered fully with no residual symptoms.

Figure 3. Case 2. Twenty-nine-year-old female experienced sudden severe headache and nausea, but stayed home until next morning when relatives called an ambulance. She was initially conscious, but lost consciousness on the way to the hospital. A) CT scan revealed severe intraventricular bleeding and hydrocephalus, and the patient was admitted to our department. She regained consciousness after ventriculostomy but was kept intubated and ventilated. B, C) DSA revealed a small Spetzler-Martin grade 3 AVM in the right cerebellar peduncle, fed by right SCA and draining to the straight sinus. D) Despite external ventricular drainage and controlled ventilation, the patient started again to deteriorate. This was attributed to brainstem compression due to expansive IV ventricle hematoma, as seen in this T1-weighted MRI scan. On day 10 after the haemorrhage, the patient was operated in sitting position via midline suboccipital approach, to evacuate the IV ventricle hematoma and resect the AVM. E, F) Postoperative DSA control demonstrated complete eradication of the AVM. G) Postoperative CT with open IV ventricle and clean AVM resection cavity. On the second postoperative day, the patient deteriorated further, she was not reactive to pain and dilated her right pupil. A wide-spread ischemia on the right MCA and ACA territories was diagnosed, and urgent right-sided decompressive hemicraniectomy was performed. H, I, J) The reason for anterior circulation infarction was a widespread vasospasm affecting both ICA territories and basilar artery, as demonstrated by left and right carotid DSA (H, I) and CTA (J) images. The situation progressed despite the hemicraniectomy, and infarcts developed also in the left hemisphere because of the vasospasm. Patient died five days after the craniectomy. 


\section{ACCEPTED MANUSCRIPT}

Table 1, anatomical and demographic data of the cohort

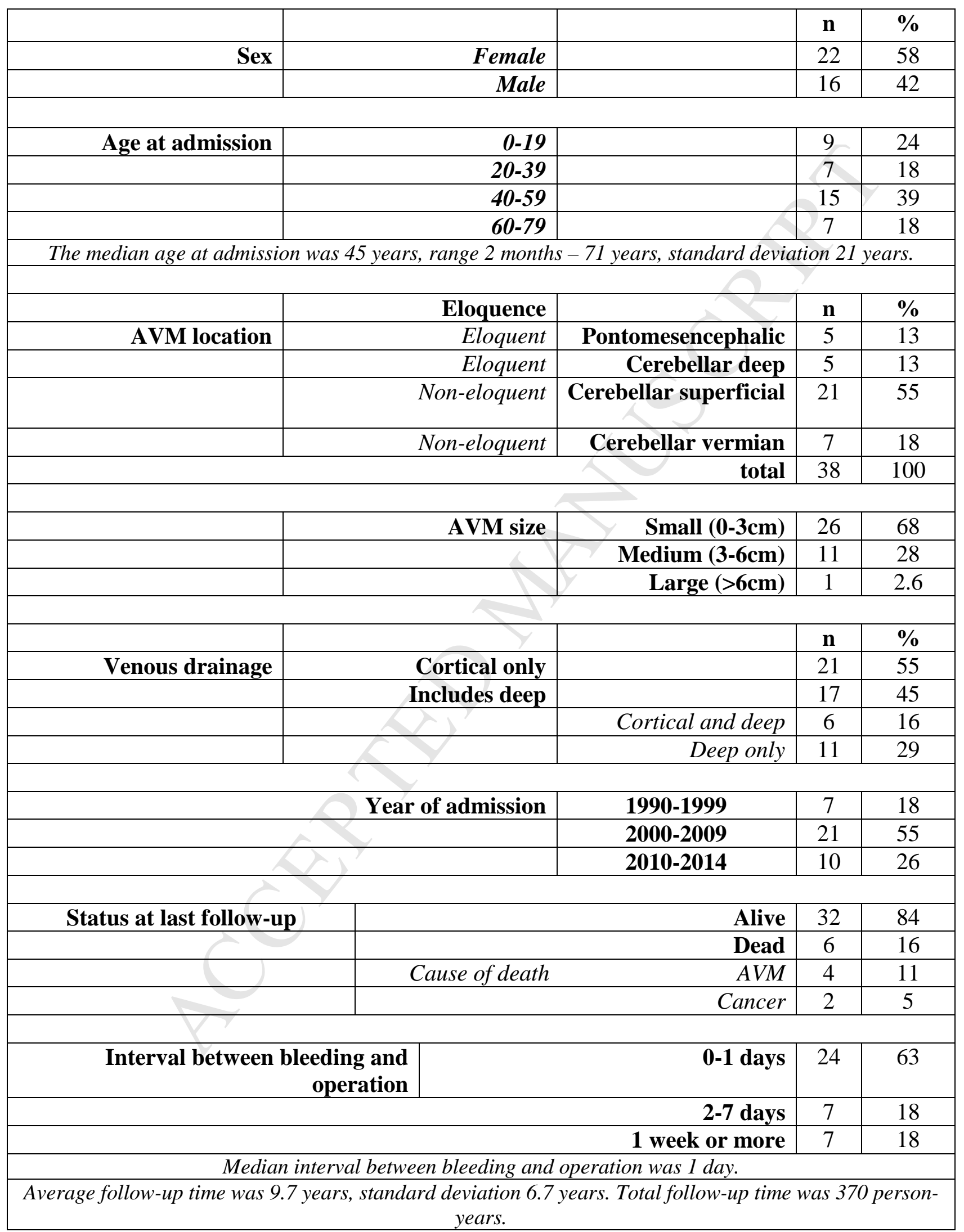


Table 2, outcome univariate analyses

\begin{tabular}{|c|c|c|c|c|c|c|c|}
\hline & \multicolumn{2}{|c|}{$\begin{array}{c}\text { Outcome at 2-4 months after } \\
\text { surgery (GOS) }\end{array}$} & \multirow[t]{2}{*}{$\begin{array}{c}\text { Total } \\
(\%)\end{array}$} & \multicolumn{2}{|c|}{$\begin{array}{l}\text { Outcome at last follow- } \\
\text { up (mRs) }\end{array}$} & \multirow[t]{2}{*}{$\begin{array}{c}\text { Total } \\
(\%)\end{array}$} \\
\hline & & Favourable & Poor & & Favourable & Poor & \\
\hline $\begin{array}{l}\text { Preoperative } \\
\text { S-M Grade }\end{array}$ & $\mathbf{I}$ & 12 & 2 & $\begin{array}{c}14 \\
(37 \%)\end{array}$ & 11 & 1 & $\begin{array}{c}12 \\
(33 \%)\end{array}$ \\
\hline & II & 8 & 3 & $\begin{array}{c}11 \\
(29 \%)\end{array}$ & 6 & 5 & $\begin{array}{c}11 \\
(31 \%)\end{array}$ \\
\hline & III & 5 & 5 & $\begin{array}{c}10 \\
(26 \%)\end{array}$ & 5 & 5 & $\begin{array}{c}10 \\
(28 \%)\end{array}$ \\
\hline & IV & 2 & 1 & $\begin{array}{c}3 \\
(7.9 \%)\end{array}$ & 2 & $y$ & $\begin{array}{c}3 \\
(8.3 \%)\end{array}$ \\
\hline \multicolumn{2}{|c|}{ Total } & $27(71 \%)$ & $11(29 \%)$ & 38 & $24(67 \%)$ & $12(33 \%)$ & 36 \\
\hline \multicolumn{4}{|c|}{$S-M^{*} G O S, p=.265$, Fisher's Exact test, two-sided. } & \multicolumn{4}{|c|}{$\begin{array}{c}S-M * m R s, p=.118, \text { Fisher's Exact test, two- } \\
\text { sided. }\end{array}$} \\
\hline & & \multicolumn{2}{|l|}{ Favourable } & $\begin{array}{l}\text { Total } \\
(\%)\end{array}$ & Favourable & Poor & $\begin{array}{l}\text { Total } \\
(\%)\end{array}$ \\
\hline $\begin{array}{l}\text { Preoperative } \\
\text { Hunt\&Hess* }\end{array}$ & 1 & 0 & 2 & $\begin{array}{c}2 \\
(5.6 \%)\end{array}$ & 1 & 1 & $\begin{array}{c}2 \\
(5.9 \%)\end{array}$ \\
\hline & 2 & 7 & 2 & $\begin{array}{c}9 \\
(25 \%)\end{array}$ & 6 & 2 & $\begin{array}{c}8 \\
(24 \%)\end{array}$ \\
\hline & 3 & 11 & 0 & $\begin{array}{c}11 \\
(31 \%)\end{array}$ & 10 & 1 & $\begin{array}{c}11 \\
(32 \%)\end{array}$ \\
\hline & 4 & 3 & & $\begin{array}{c}4 \\
(11 \%) \\
\end{array}$ & 2 & 1 & $\begin{array}{c}3 \\
\mathbf{8 . 8 \%}\end{array}$ \\
\hline & 5 & 4 & 6 & $\begin{array}{c}10 \\
(28 \%)\end{array}$ & 4 & 6 & $\begin{array}{c}10 \\
(29 \%)\end{array}$ \\
\hline & otal & $25(69 \%)$ & $11(31 \%)$ & 36 & $23(66 \%)$ & $11(32 \%)$ & 34 \\
\hline \multicolumn{4}{|c|}{$H \& H^{*} G O S, p=.003$, Fisher's exact test, two-sided. } & \multicolumn{4}{|c|}{$\begin{array}{c}H \& H * m R s, p=.112, \text { Fisher's exact test, two- } \\
\text { sided. }\end{array}$} \\
\hline \multicolumn{8}{|c|}{ *two Hunt\&Hess values could not have been reliably estimated retrospectively } \\
\hline \multicolumn{8}{|c|}{ 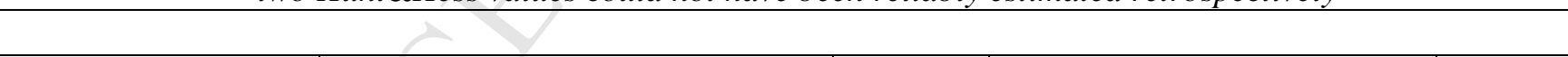 } \\
\hline \multicolumn{2}{|c|}{$\begin{array}{l}\text { Flow of venous } \\
\text { drainage }\end{array}$} & \multicolumn{2}{|c|}{ Favourable } & $\begin{array}{l}\text { Total } \\
(\%)\end{array}$ & \multicolumn{2}{|l|}{ Favourable } & $\begin{array}{l}\text { Total } \\
(\%)\end{array}$ \\
\hline Cortical & only & 18 & 3 & $\begin{array}{c}21 \\
(55 \%)\end{array}$ & 16 & 3 & $\begin{array}{c}19 \\
(53 \%)\end{array}$ \\
\hline Including & deep & 9 & 8 & $\begin{array}{c}17 \\
(45 \%)\end{array}$ & 8 & 9 & $\begin{array}{c}17 \\
(47 \%)\end{array}$ \\
\hline Cortical and & deep & 6 & 0 & $\begin{array}{c}6 \\
(16 \%)\end{array}$ & 4 & 2 & $\begin{array}{c}6 \\
(17 \%)\end{array}$ \\
\hline Deep & only & 3 & 8 & $\begin{array}{c}11 \\
(29 \%)\end{array}$ & 4 & 7 & $\begin{array}{c}11 \\
(31 \%)\end{array}$ \\
\hline & otal & $27(71 \%)$ & $11(29 \%)$ & 38 & $24(67 \%)$ & $12(33 \%)$ & 36 \\
\hline \multicolumn{4}{|c|}{$\begin{array}{c}\text { Venous drainage } * G O S, O R=5.33, \text { CI 1.13-25.1, } \\
p=.037, \text { Fisher's exact test, two-sided }\end{array}$} & \multicolumn{4}{|c|}{$\begin{array}{l}\text { Venous drainage } * m R s, O R=6.00, \text { CI 1.26- } \\
28.5, p=.33, \text { Fisher's exact test, two-sided }\end{array}$} \\
\hline
\end{tabular}


Table 3, outcome distribution

\begin{tabular}{|c|c|c|c|c|}
\hline \multirow[t]{7}{*}{ Outcome at 2-4 months after surgery } & GOS & & $\mathrm{n}$ & $\%$ \\
\hline & 5 & Good recovery & 14 & 37 \\
\hline & 4 & Moderate disability & 13 & 34 \\
\hline & 3 & Severe disability & 6 & 16 \\
\hline & 2 & Vegetative stage & 1 & 2.6 \\
\hline & $\mathbf{1}$ & Dead & 4 & 11 \\
\hline & & total & 38 & 100 \\
\hline \multicolumn{5}{|c|}{$x^{\prime}$} \\
\hline \multirow[t]{9}{*}{ Outcome at last follow-up } & mRs & +2 & $\mathrm{n}$ & $\%$ \\
\hline & $\mathbf{0}$ & No symptoms & 7 & 19 \\
\hline & $\mathbf{1}$ & No disability despite symptoms & 8 & 22 \\
\hline & 2 & $\begin{array}{l}\text { Slight disability } \\
\end{array}$ & 9 & 25 \\
\hline & 3 & Moderate disability & 3 & 8.3 \\
\hline & 4 & Moderately severe disability & 3 & 8.3 \\
\hline & 5 & Severe disability & 2 & 5.6 \\
\hline & 6 & Dead (AVM related reason) & 4 & 11 \\
\hline & & total & 36 & 100 \\
\hline
\end{tabular}


Table 4, summary of previous studies

\begin{tabular}{|c|c|c|c|c|c|c|}
\hline \multicolumn{3}{|c|}{$\begin{array}{l}\text { Main treatment modality in } \\
\text { the study, first author }\end{array}$} & $\begin{array}{c}\text { Endovascular, } \\
\text { T Robert, 1995- } \\
2013\end{array}$ & $\begin{array}{c}\text { Radiosurgery, } \\
\text { D Ding, 1989- } \\
\mathbf{2 0 1 3}\end{array}$ & $\begin{array}{l}\text { Multimodal } \\
\text { therapy, } \\
\text { ME Kelly, } \\
\text { 1982-2006 }\end{array}$ & $\begin{array}{c}\text { Microsurgery, } \\
\text { A Pohjola, 1990- } \\
2016\end{array}$ \\
\hline \multicolumn{3}{|c|}{ Number of patients } & 69 & 60 & 48 & 38 \\
\hline \multirow[t]{2}{*}{ Sex } & & male & $46(67 \%)$ & $25(42 \%)$ & $22(46 \%)$ & $16(42 \%)$ \\
\hline & & male & $23(33 \%)$ & $35(58 \%)$ & $26(54 \%)$ & $22(58 \%)$ \\
\hline \multicolumn{3}{|c|}{$\begin{array}{r}\text { Mean age at diagnosis (range), } \\
\text { years }\end{array}$} & $34(4-67)$ & $36(5.9-67)$ & $34(12-73)$ & $40(0.19-71)$ \\
\hline \multicolumn{3}{|c|}{ Associated aneurysms } & $28(44 \%)$ & - & $10(21 \%)$ & $6(16 \%)$ \\
\hline \multirow[t]{3}{*}{ Location } & cer & llum & $58(84 \%)$ & $60(100 \%)$ & $13(27 \%)$ & $33(87 \%)$ \\
\hline & & stem & $11(16 \%)$ & 0 & $29(60 \%)$ & $5(13 \%)$ \\
\hline & & ined & - & 0 & $6(13 \%)$ & 0 \\
\hline \multicolumn{3}{|c|}{ Mean size (range), cm } & - & $1.9(0.6-3.7)$ & $3.1(0.5-7.0)$ & $2.7(0.3-6.0)$ \\
\hline \multirow[t]{3}{*}{ Size distribution } & & Omm & $48(70 \%)$ & $42(70 \%)$ & - & $26(68 \%)$ \\
\hline & & Omm & $21(30 \%)$ & $18(30 \%)$ & - & $11(29 \%)$ \\
\hline & & $\mathbf{n m +}$ & 0 & 0 & - & $1(2.6 \%)$ \\
\hline \multirow[t]{3}{*}{ Venous drainage } & & ficial & $30(44 \%)$ & $30(50 \%)$ & $18(38 \%)$ & $21(55 \%)$ \\
\hline & & deep & $23(33 \%)$ & $30(50 \%)$ & $30(63 \%)$ & $17(45 \%)$ \\
\hline & & both & $16(23 \%)$ & - & - & $6(16 \%)$ \\
\hline & & $\sqrt{y}$ & & \\
\hline \multicolumn{3}{|c|}{ Haemorrhage at presentation } & $57(83 \%)$ & $41(68 \%)$ & $37(77 \%)$ & $38(100 \%)$ \\
\hline \multicolumn{3}{|c|}{ Mean follow-up (range), years } & $2.4(0.20-11)$ & $6.2(0.60-16)$ & $4.8(0.10-18)$ & $9.7(0.02-26)$ \\
\hline \multicolumn{3}{|c|}{$\begin{array}{l}\text { Obliteration rate with the main } \\
\text { treatment modality }\end{array}$} & $50(73 \%)$ & $43(72 \%)$ & $21(62 \%)$ & $36(95 \%)$ \\
\hline \multirow{2}{*}{\multicolumn{3}{|c|}{ Outcome at last follow-up }} & GOS 1-3: $15(22 \%)$ & Poor: $18(30 \%)$ & \multirow{2}{*}{$\begin{array}{l}\text { Mean GOS: } \\
3.8\end{array}$} & GOS 1-3: $9(25 \%)$ \\
\hline & & & GOS 4-5: $54(78 n \%)$ & $\begin{array}{l}\text { *Favourable: } \\
42(70 \%)\end{array}$ & & GOS 4-5: $27(75 \%)$ \\
\hline \multirow{3}{*}{\multicolumn{2}{|c|}{ S-M grades at admission }} & $<3$ & $39(57 \%)$ & $50(83 \%)$ & 0 & $25(66 \%)$ \\
\hline & & 3 & $18(26 \%)$ & $9(15 \%)$ & \multirow{2}{*}{$\begin{array}{c}\text { **Mean S-M: } \\
3.1\end{array}$} & $10(26 \%)$ \\
\hline & & 4 & $12(17 \%)$ & $1(1.6 \%)$ & & $3(7.9 \%)$ \\
\hline
\end{tabular}




\section{ACCEPTED MANUSCRIPT}

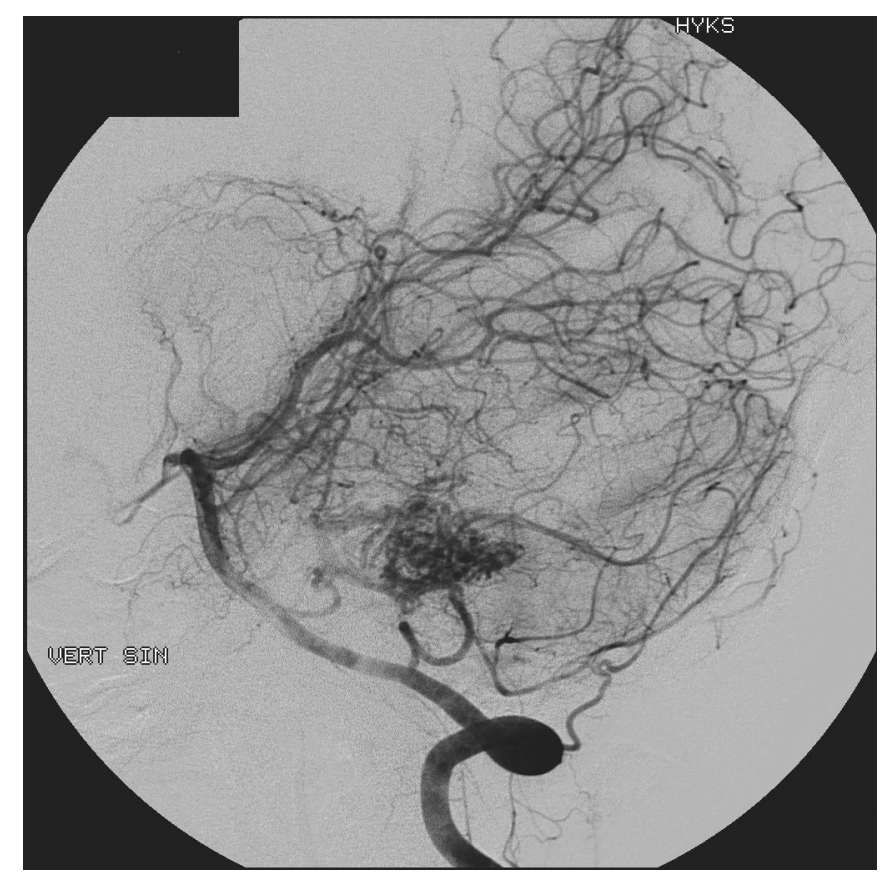


Figure 1, flowchart of patient selection to statistical analyses

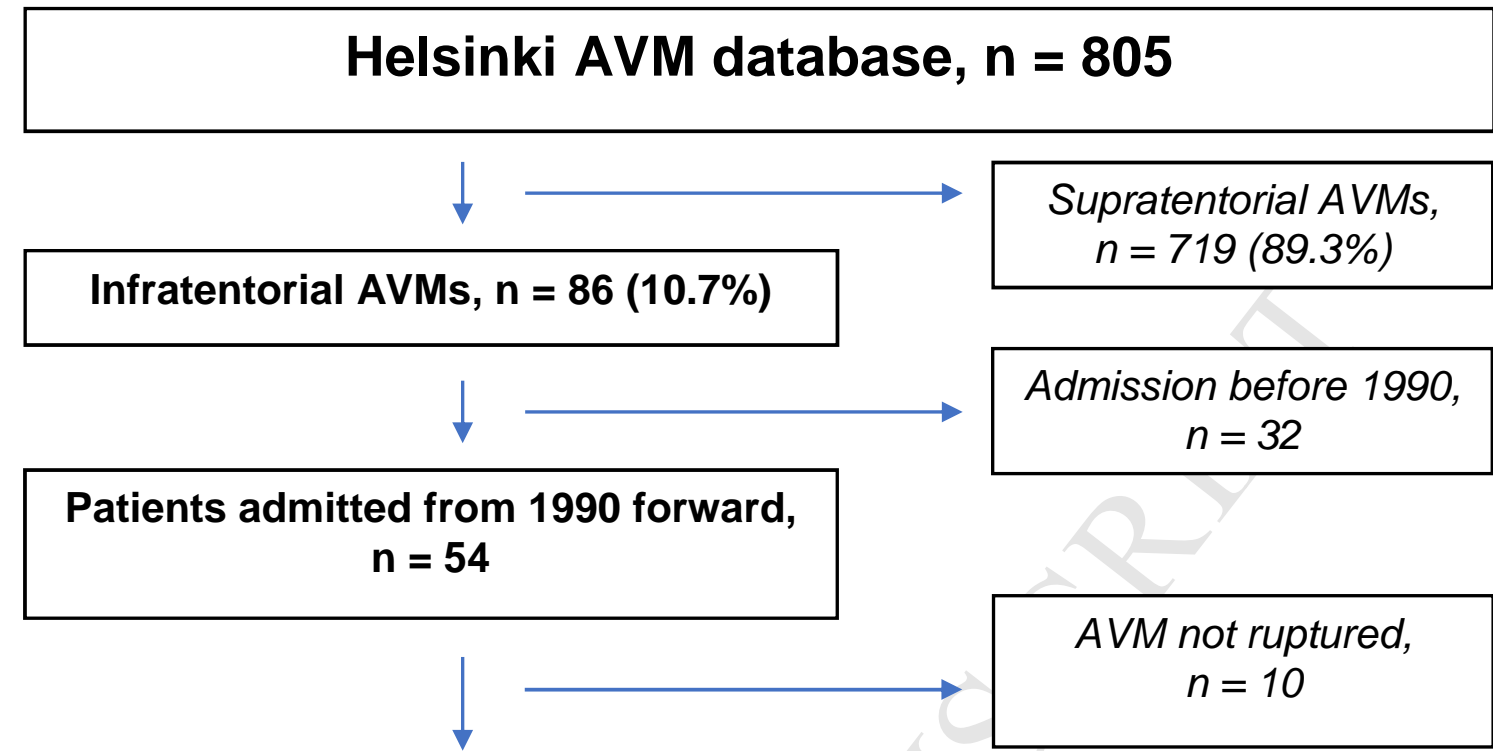

AVM ruptured before treatment, $n=44$

No surgical treatment, $n=5$

Initial treatment abroad, $n=1$

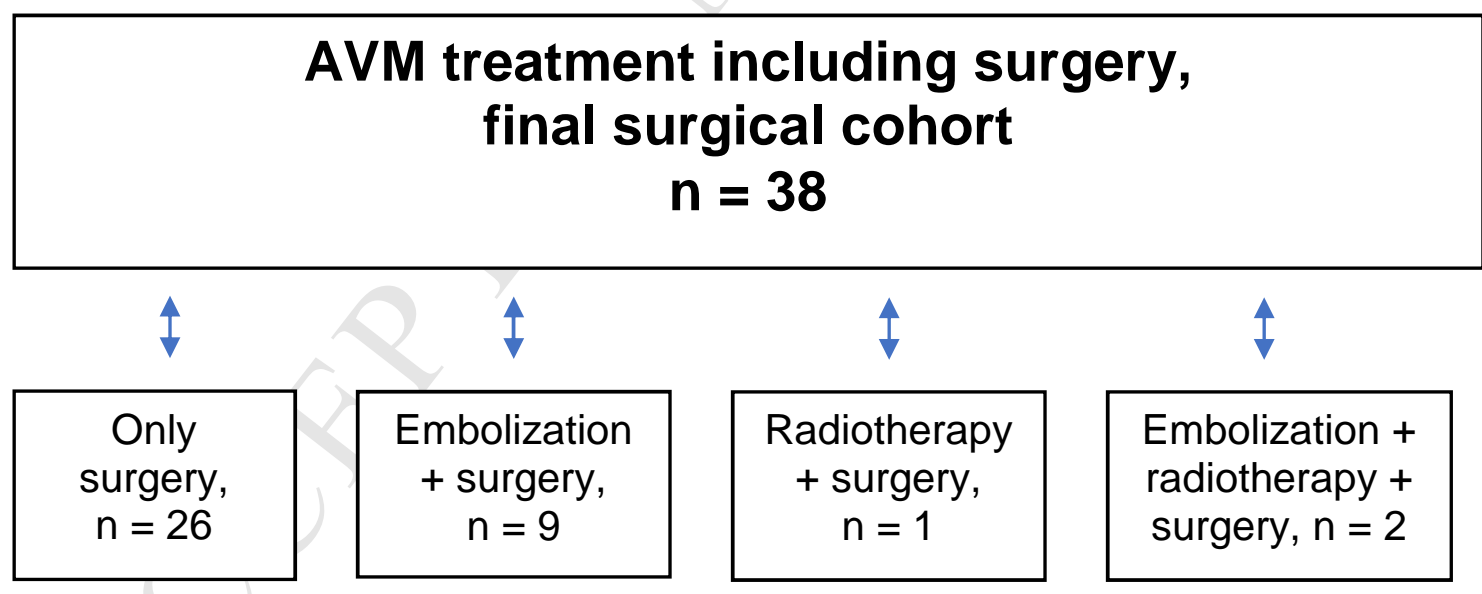




\section{ACCEPTED MANUSCRIPT}

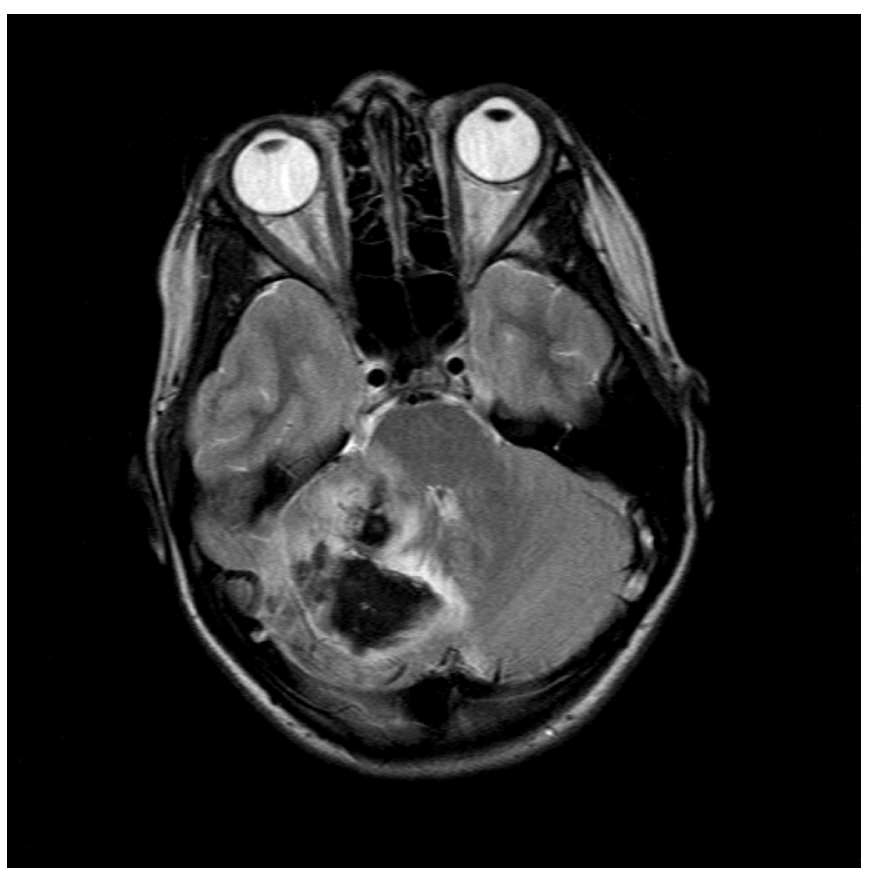




\section{ACCEPTED MANUSCRIPT}

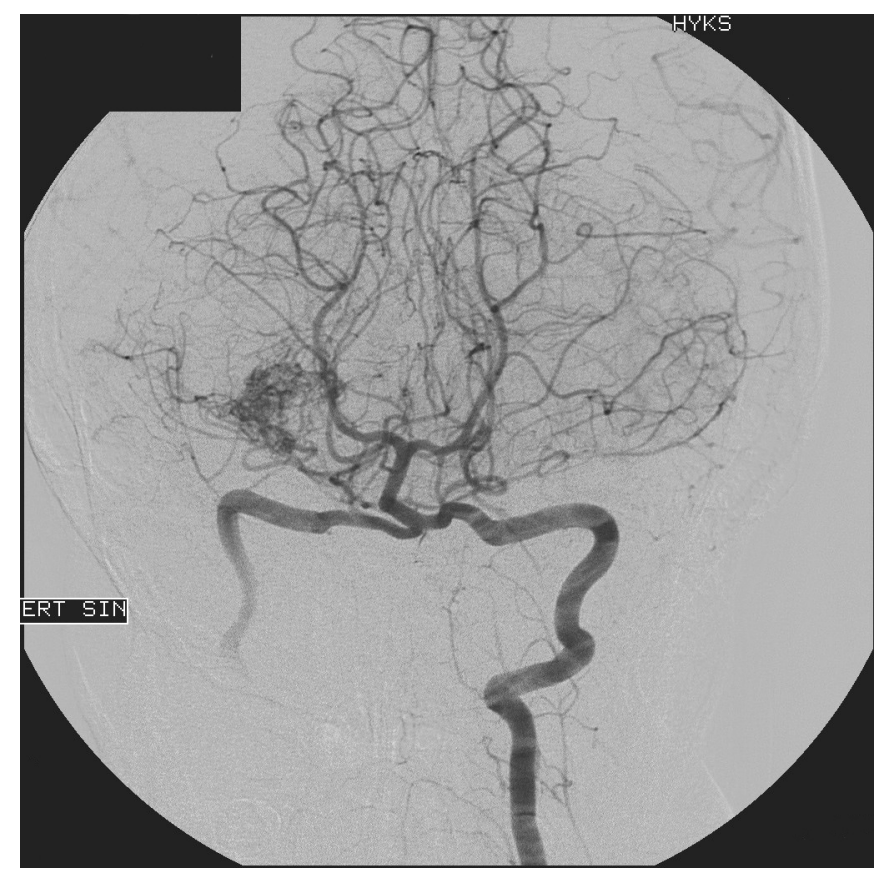




\section{ACCEPTED MANUSCRIPT}

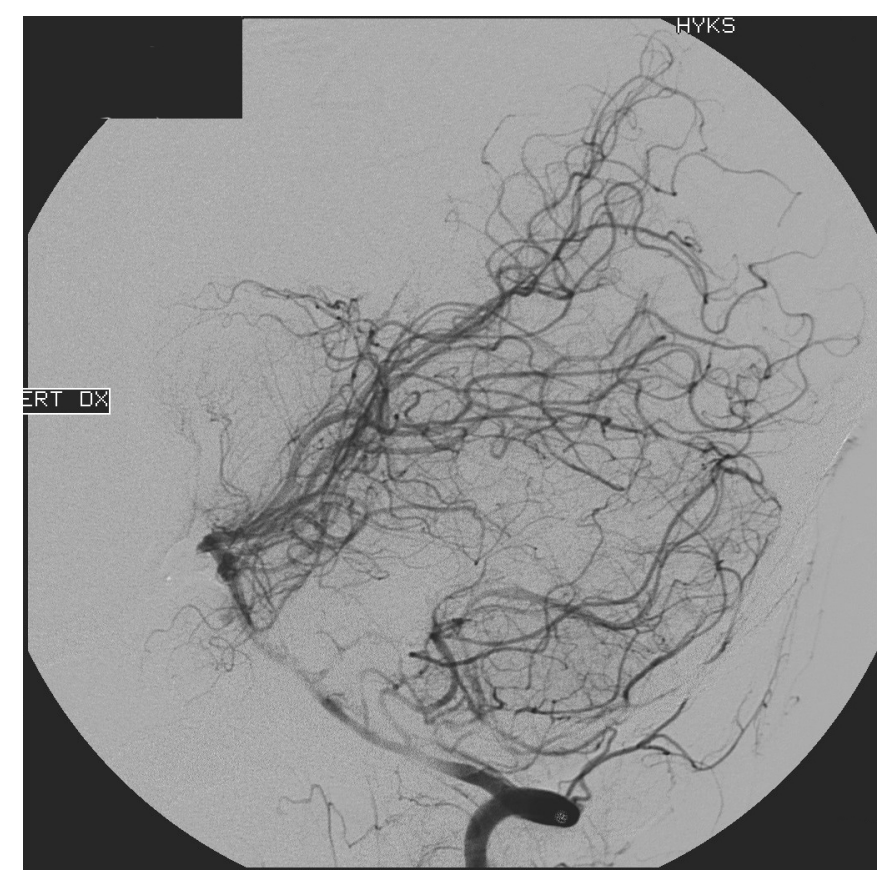




\section{ACCEPTED MANUSCRIPT}

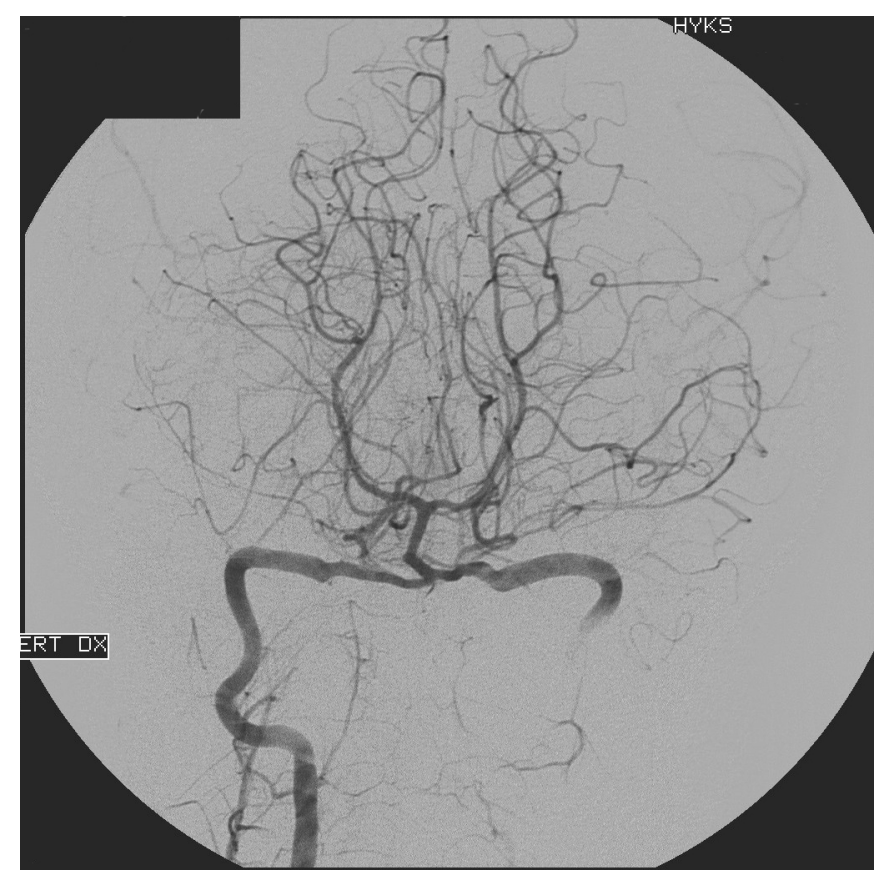




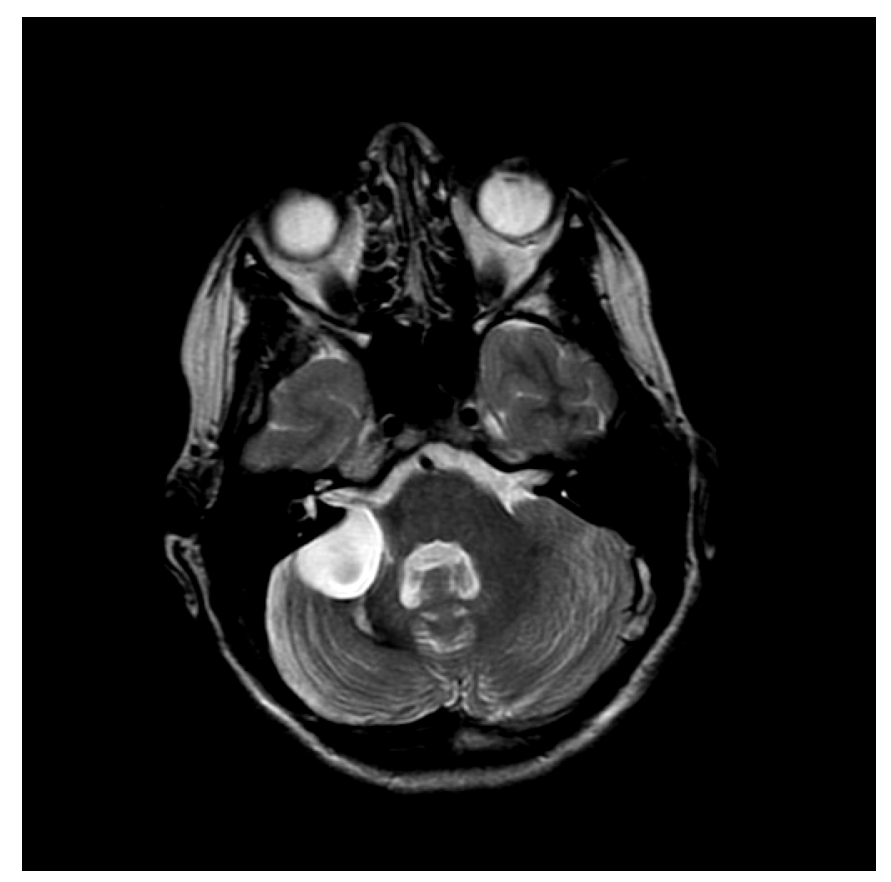




\section{ACCEPTED MANUSCRIPT}

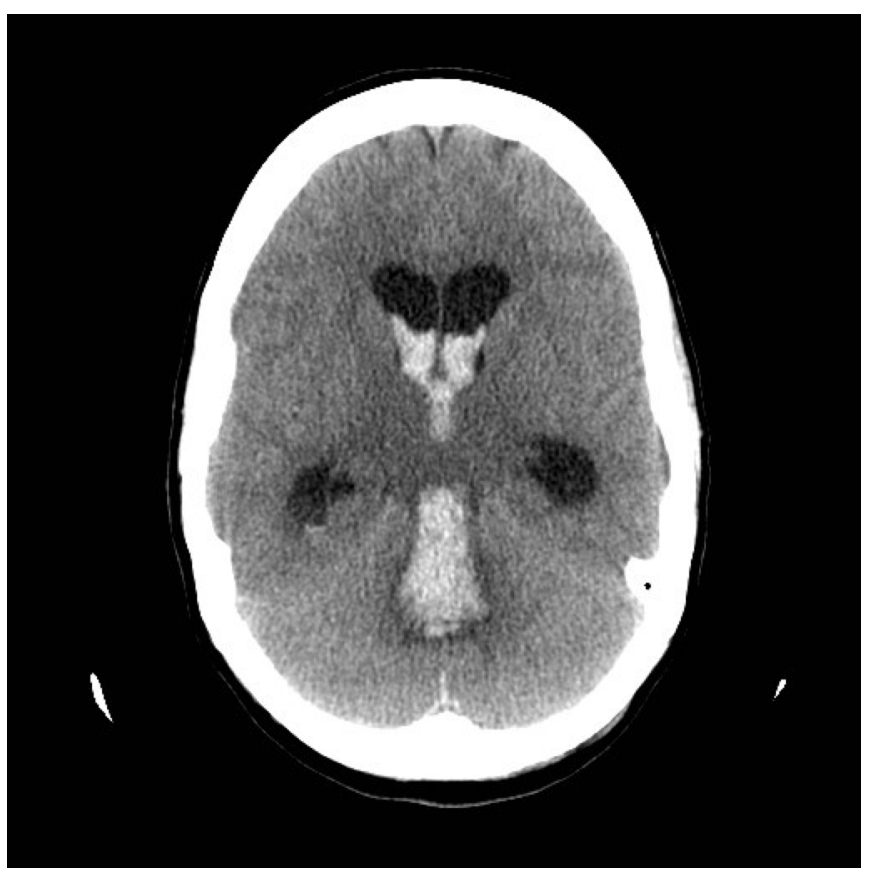




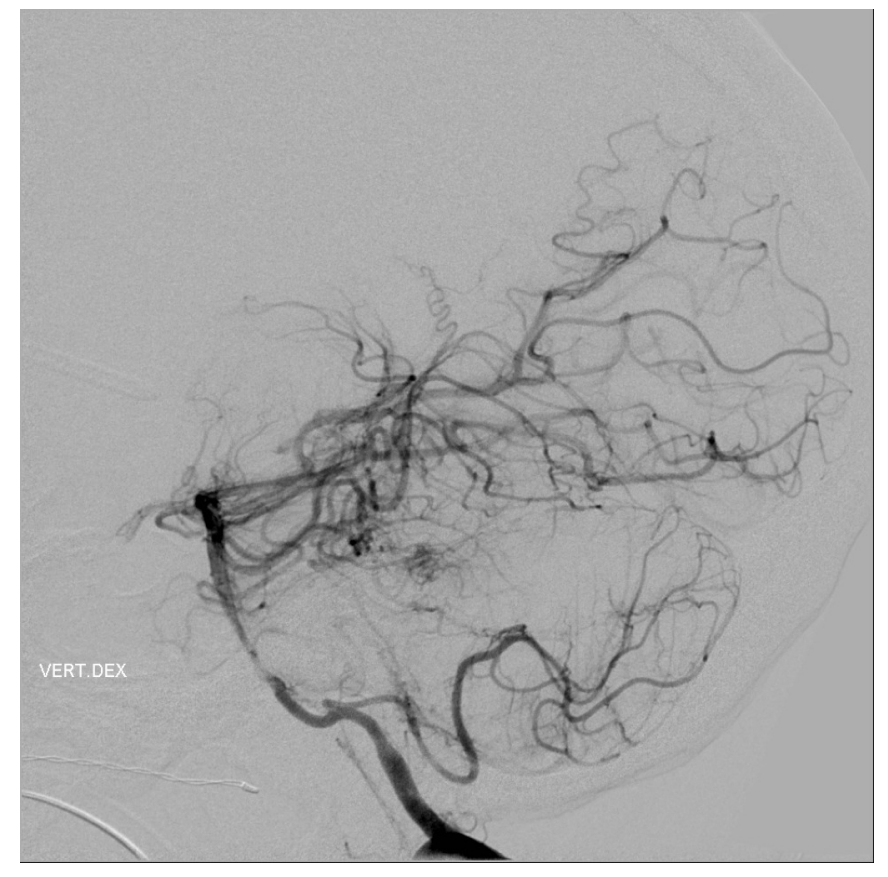




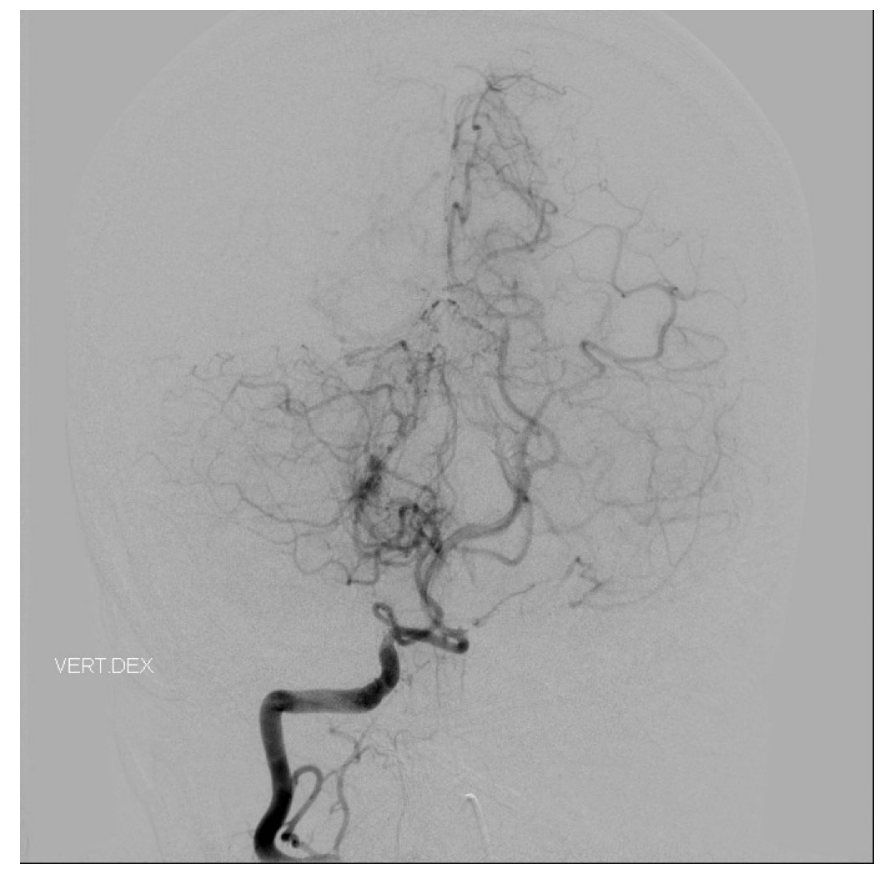




\section{ACCEPTED MANUSCRIPT}

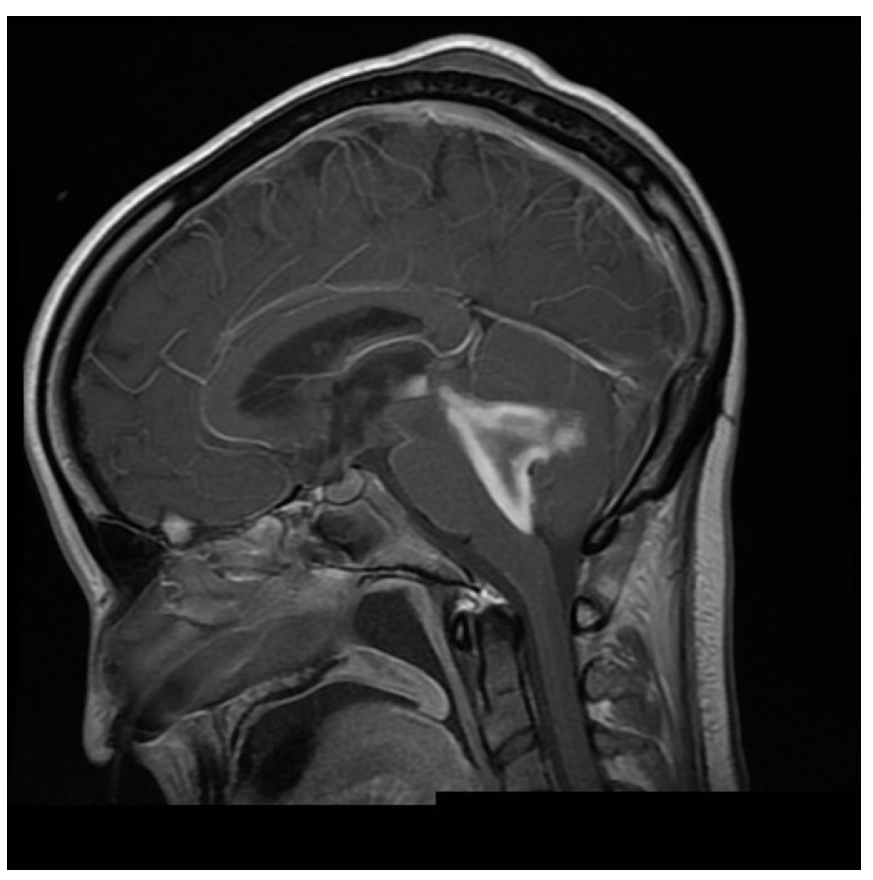




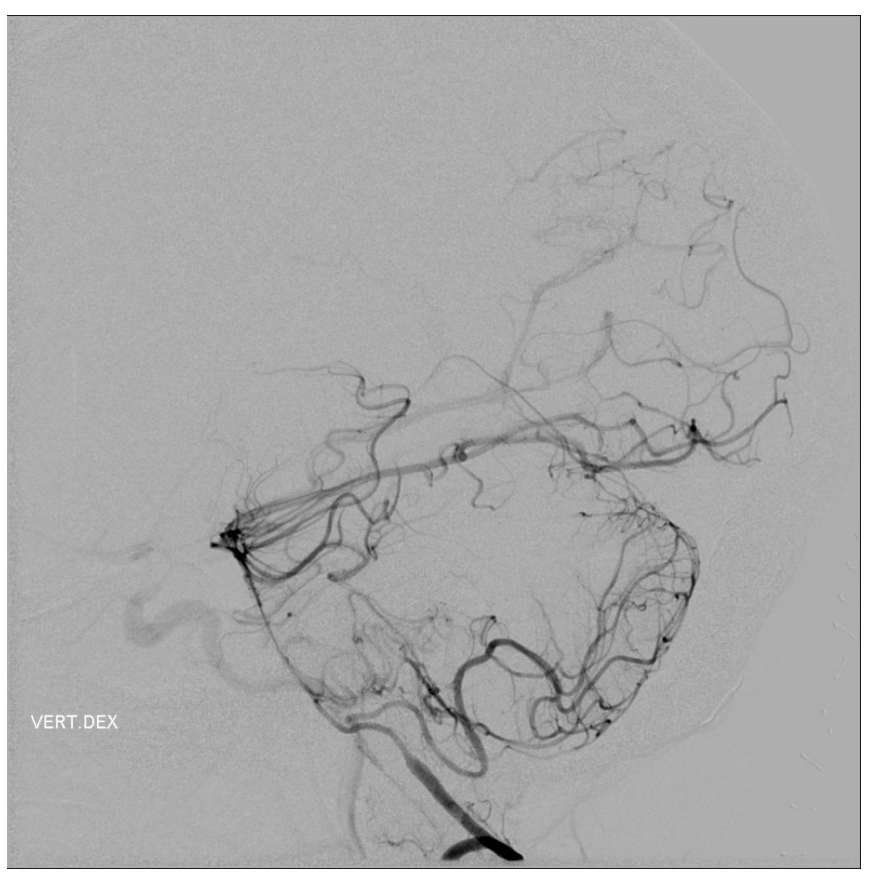




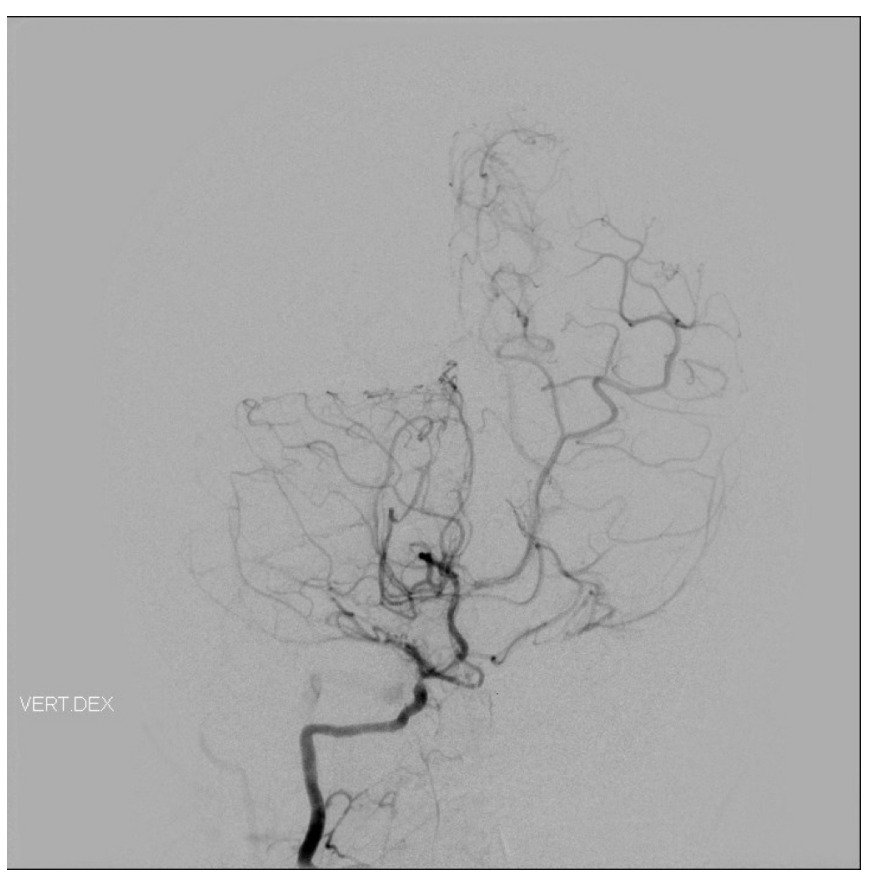




\section{ACCEPTED MANUSCRIPT}

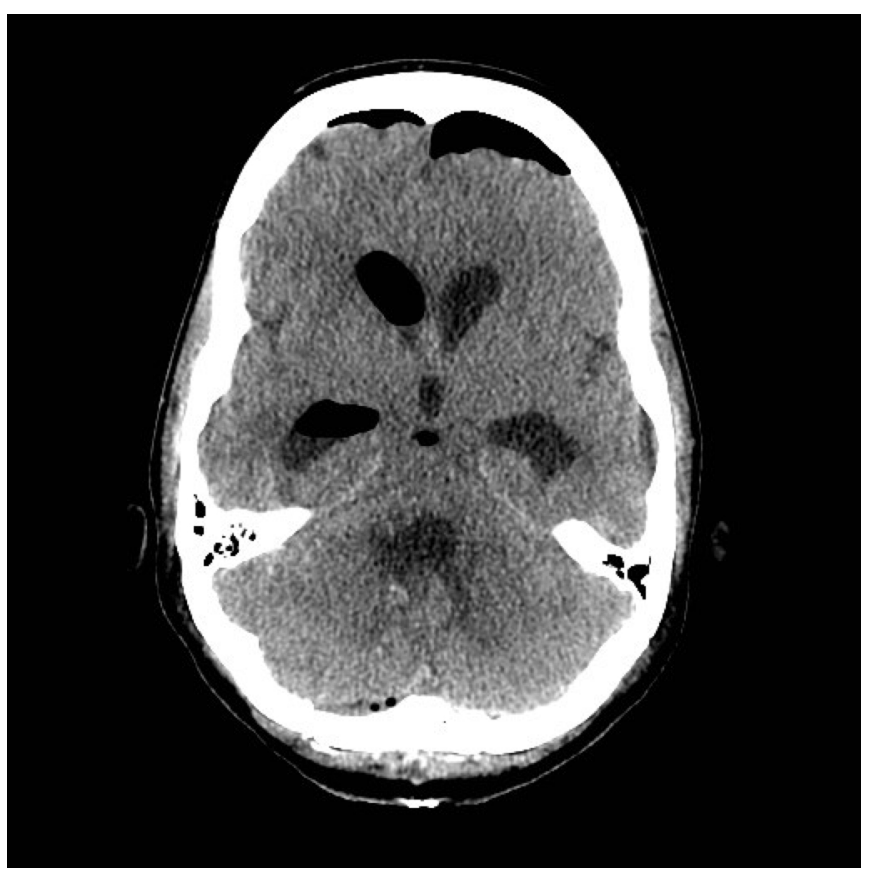




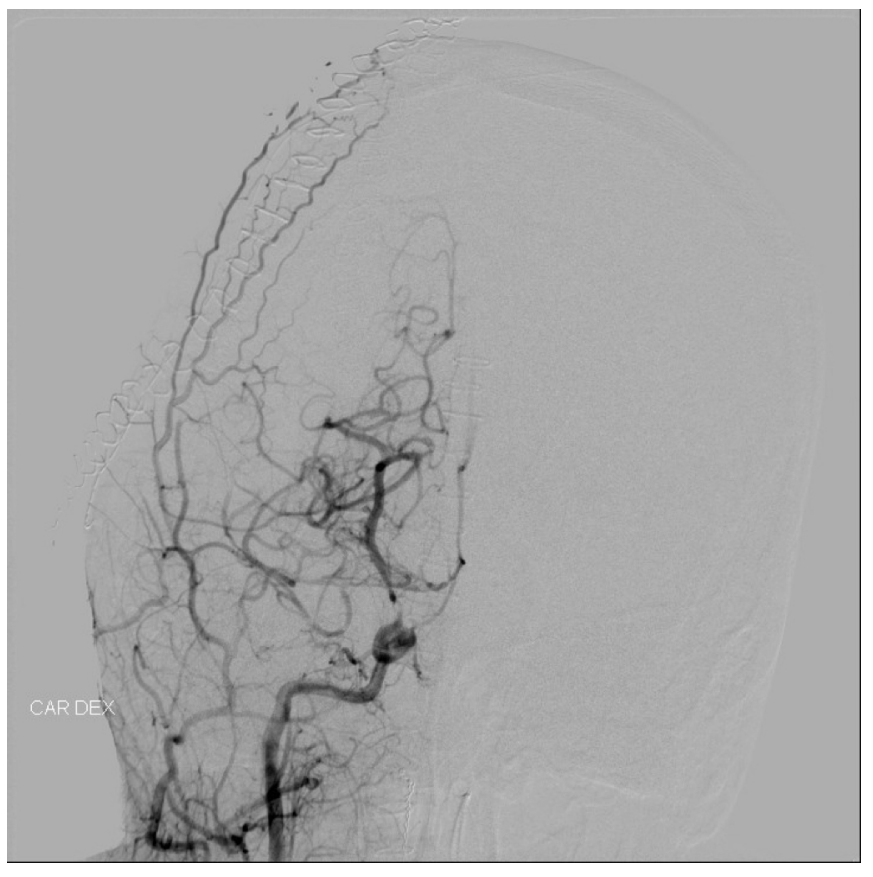




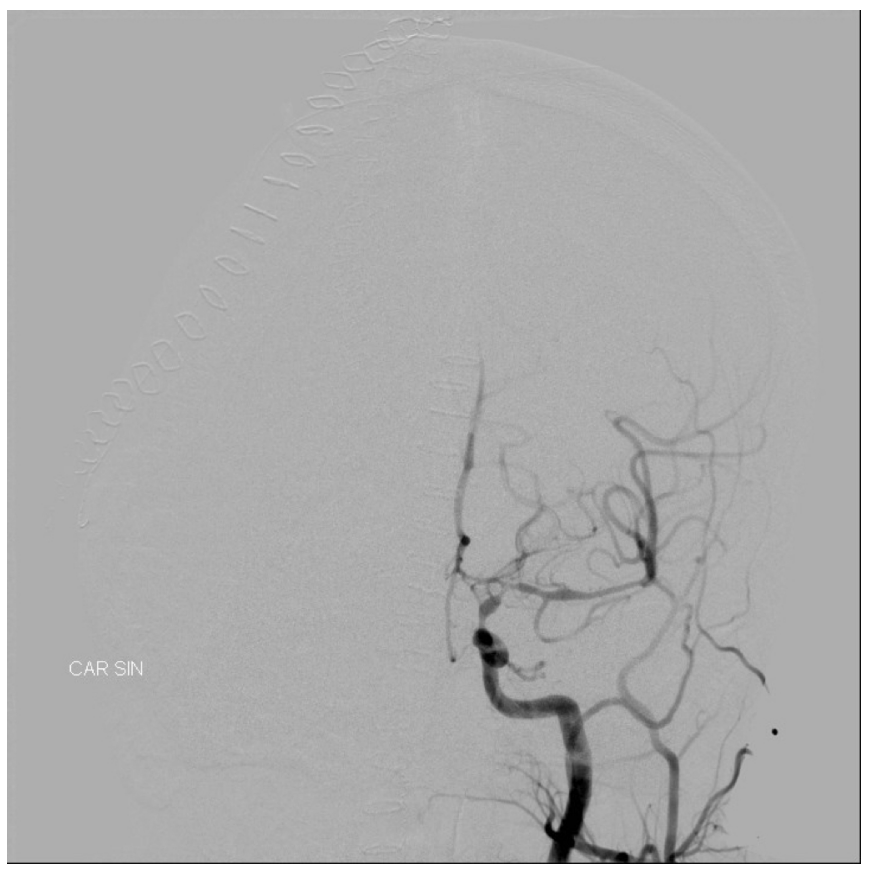




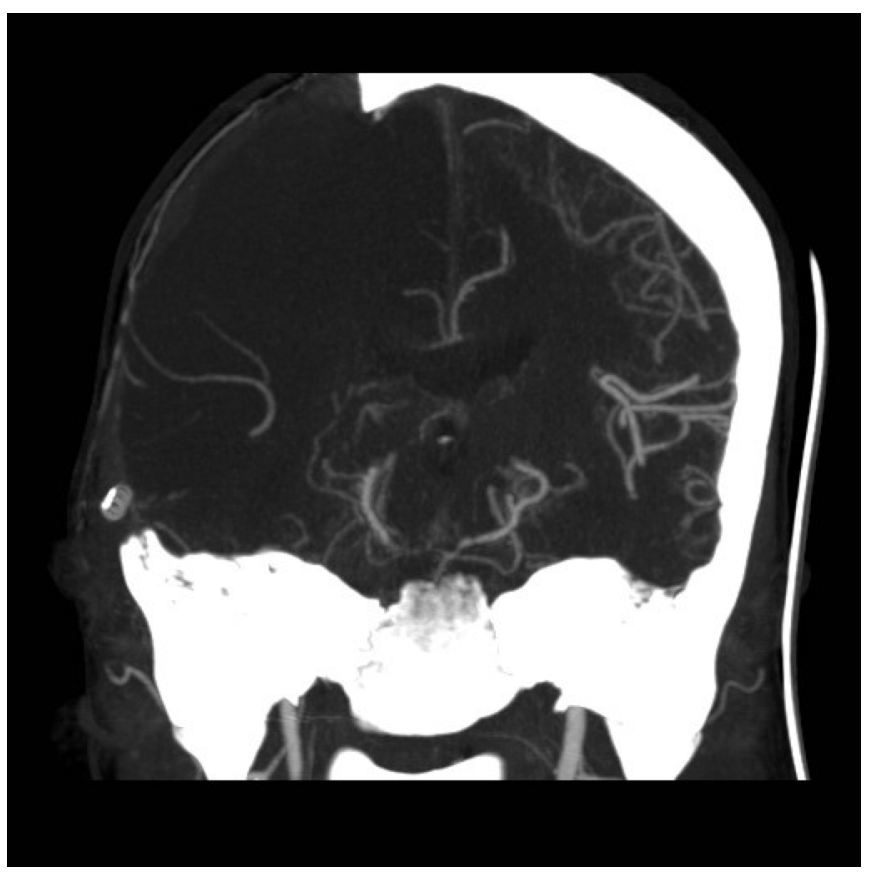


Highlights

- Venous drainage pattern has the most significant influence on patient's outcome after surgery, favouring patients with only cortical drainage.

- The severity of the bleeding influences patient's outcome after surgery.

- Even after a rupture of a treacherous infratentorial, even eloquently located AVM, patient's clinical condition can reach favorable outcomes with surgical intervention.

- We need more similar outcome analyses on these rare lesions from other research groups and patient cohorts. 


\section{Abbreviations}

ACA - anterior cerebral artery

AVM - arteriovenous malformation

DSA - digital subtraction angiography

$\mathrm{CI}$ - confidence interval

CSF shunt - cerebrospinal fluid shunt

CT - computed tomography

CTA - computed tomography angiography

GOS - Glasgow outcome scale

H\&H - Hunt \& Hess scale

ICA - internal carotid artery

MCA - middle cerebral artery

MRI - magnetic resonance imaging

mRs - modified Rankin scale

OR - odds ratio

PICA - posterior inferior cerebellar artery

RIC - radiation induced changes

SCA - superior cerebellar artery

S-M - Spetzler-Martin grading system 
Declaration of interest

We wish to confirm that there are no known conflicts of interest associated with this publication and there has been no significant financial support for this work that could have influenced its outcome.

We confirm that the manuscript has been read and approved by all named authors and that there are no other persons who satisfied the criteria for authorship but are not listed. We further confirm that the order of authors listed in the manuscript has been approved by all of us.

We confirm that we have given due consideration to the protection of intellectual property associated with this work and that there is no impediment to publication, including the timing of publication, with respect to intellectual property. In so doing we confirm that we have followed regulations of our institutions concerning intellectual property.

We understand that the Corresponding Author is the sole contact for the Editorial process (including Editorial Manager and direct communications with the office). He is responsible for communicating with the other authors about progress, submissions of revisions and final approval of proofs. We confirm that we have provided a current, correct email address which is accessible by the Corresponding Author.

Signed by all authors as follows:

Anni Pohjola

Hanna Lehto

Ahmad Hafez

Elias Oulasvirta

Päivi Koroknay-Pál

Aki Laakso

18th May 2018 